\title{
BIG DATA ANALYTICS IN INTERNAL AUDIT
}

\section{DOI: 10.17261/Pressacademia.2018.893 \\ PAP- V.7-2018(46)-p.260-262}

Idil Kaya ${ }^{1}$, Destan Halit Akbulut ${ }^{2}$, Koray Ozoner ${ }^{3}$

${ }^{1}$ Galatasaray University, Istanbul, Turkey.

ikaya@gsu.edu.tr, ORCID: 0000-0002-9171-5989

${ }^{2}$ Galatasaray University, Istanbul, Turkey.

dhakbulut@gsu.edu.tr, ORCID: 0000-0002-0705-9553

${ }^{3}$ Galatasaray University, Istanbul, Turkey.

korayozoner@hotmail.com, ORCID: 0000-0003-0602-1163

To cite this document

Kaya, I., Akbulut, D. H., Ozoner, K. (2018). Big data analytics in internal audit. PressAcademia Procedia (PAP), V.7, p.260-262.

Permanent link to this document: http://doi.org/10.17261/Pressacademia.2018.893

Copyright: Published by PressAcademia and limited licenced re-use rights only.

\section{ABSTRACT}

Purpose- This paper aims to analyze the role and effects of big data analytics on internal audit. To achieve this aim, we try to define the big data analytics and its impact on internal audit. As a course of nature of the internal audit, analytical review procedures are embedded in internal control models and fraud detection techniques. Since big data merge massive amounts of a diverse type of information with various kind of analytical tools, we also try to determine what big data analytics offer to the development of internal audit function.

Methodology- The research design is exploratory research based on a focus group to generate knowledge from different perspectives. We benefit group interaction and try to discover how internal auditors view big data and its effects on the internal audit. We also investigate the ways of implementation the big data analytics in the organization, such as hiring new analytically trained professionals or using the services of third-party solutions providers for big data.

Findings- We find similar results with the literature that big data analytics increase the effectiveness of internal audit. Using analytics in internal control, risk management and fraud detection have many benefits in identifying anomalies and exceptions and focusing more on correlation and causation.

Conclusion- Internal auditors are mostly aware of the importance of big data analytics, the different policies and methods of its implementation into the organization and its role in transforming internal audit function.

Keywords: Data analytics, internal audit, big data, exploratory research

JEL Codes: M40, M41, M42

\section{INTRODUCTION}

The aim of this paper is to analyze the role and effects of big data analytics (BDA) on internal audit. To achieve this aim, we conducted a focus group study on the BDA and its impact on internal audit. As a course of nature of the internal audit, analytical review procedures are embedded in internal control models and fraud detection techniques. Since big data merge massive amounts of a diverse type of information with various kind of analytical tools, we also try to determine what big data analytics offer to the development of internal audit function.

Sun et al. (2018) defined BDA as the process of collecting, organizing, and analyzing big data to discover, visualize and display patterns, knowledge, and intelligence as well as other information within the big data. On the other hand, internal audit function evaluate and improve the effectiveness of risk management, control and governance process in organizations. Consequently, it is expected that BDA facilitates and support an operational audit of each unit, division, or entity (Tang et al., 2017). Also, BDA collects and interrogate complete datasets rather than sampling and extrapolating hence augment the accuracy of the analyses of the internal audit function. The remainder of this paper proceeds as follows. First, we review the literature. Second, we present research method and methodology. Third, we illustrate the findings of the focus group study, and we conclude.

\section{LITERATURE REVIEW}

There is a developing literatüre on the BDA impact upon the internal audit. Several academic researchers identify the benefits and opportunities of BDA in internal audit, forensic accounting, and fraud detection. 
Protiviti's "2017 Internal Audit Capabilities and Needs Survey" analyze data analytics and the audit process, general technical knowledge, audit process knowledge and personal skills and capabilities of 906 participants with different industries such as manufacturing, U.S. financial services, and U.S. healthcare industries.

This survey found five crucial factor of data analytics and internal audit.

- Data analytics is gaining a foothold in internal auditing.

- Most internal audit shops are still in their "analytics infancy."

- The more sophisticated analytics capabilities are, the higher value they're perceived to deliver.

- Cybersecurity, cloud, mobile tech, and big data are top-of-mind.

- Business and digital transformation are drawing more attention.

Alves and Matos (2010) examine the reasons for implementation of ERP systems. They found that companies remove ERP systems because of the competitive environment, demand for real-time information, obtain information for decision-making and integration of applications.

Cangemi (2016) found that the use of technology continues to grow in terms of the audit process. This paper suggests that internal auditors have to use big data analytics technologies to improve, contribute to and enhance their internal audit process.

Tang, Norman, and Vendrzyk (2017) research the use of data analytics in the internal audit process. They use a case study approach, and their sample includes Chief Audit Executive in six for-profit companies and six not-for-profit organizations. They found that the demand for data analytics will continue to increase and within five years enterprises' internal audit departments need additional employees who know data analytics technologies. They also underline that this change will affect many universities' schedules and programmes.

\section{RESEARCH METHOD AND METHODOLOGY}

The research design is exploratory research based on a focus group to generate knowledge from different perspectives. We benefit group interaction and try to discover how big data and its effects on the internal audit is viewed by internal auditors. We also investigate the ways of implementation the big data analytics in the organization, such as hiring new analytically trained professionals or using the services of third-party solutions providers for big data.

The sample of this study contains eight participants. We grouped these participants into three different categories. The points we notice while categorizing of our participants are their job position, work experience, and certificate.

Accordingly, participant 1, 2, 6, 7 take part in first category with their work experience 6 years and job position financial controller and income accounting expert. Both of them have CPA certificate.

Participant 3, 4 and 5 take part in the second category with their work experience of nearly three years. Participant 8 takes part in the third category with different job position as SAP consultant and 20 years work experience.

Table 1: Characteristics of Participant

\begin{tabular}{|c|c|c|c|c|}
\hline & Job Position & Work Experience & Certificate & $\begin{array}{l}\text { Software and ERP } \\
\text { Systems used by } \\
\text { participants }\end{array}$ \\
\hline Participant 1 & Financial Controller & 6 years & CMA, CPA & $\begin{array}{l}\text { SAP, QlikView, Qlik- } \\
\text { Sense, Excel }\end{array}$ \\
\hline Participant 2 & Accountant & 6 years & CPA & PARES, DWH \\
\hline Participant 3 & Accountant & 2 years & & SAP \\
\hline Participant 4 & Accountant & 3 years & & SAP \\
\hline Participant 5 & $\begin{array}{lr}\text { Accounting } & \text { Specialist } \\
\text { Financial } & \text { control } \\
\text { department } & \\
\end{array}$ & 5 years & & SAP \\
\hline Participant 6 & $\begin{array}{l}\text { Internal control expert in } \\
\text { the financial control } \\
\text { department }\end{array}$ & 7 years & & Excel, SAP \\
\hline Participant 7 & $\begin{array}{l}\text { Reporting Chef at Cargo } \\
\text { Department }\end{array}$ & 8 years & Master graduate & Excel, SAP \\
\hline Participant 8 & $\begin{array}{l}\text { SAP consultant, the } \\
\text { application programmer }\end{array}$ & 20 years & Computer Engineer & SAP, Excel \\
\hline
\end{tabular}

\section{FINDINGS AND INTERPRETATIONS}

We firstly ask our participants which big data analytics they used in their internal audit process, and they work for which process. Beside the BDA, they mainly use SAP modules and some visualization tools such as Click-view, click-sense. They also used Excel and some in-house software such as DWH. 
Then we ask their plans about big data analytics in internal audit. The main points are to remove manual intervention, to make first-tier employees (Front Office) to use big data analytics properly. The elimination of integration between data analytics software is also fundamental issues, and they have plans to solve this problem. This problem is also affecting the quality of data that used in the internal audit. According to participant 5, the process of internal audit becomes more systematic with the extended ERP system. Making interpretation and calculations easier than before. They get positive feedbacks and comments on this issue.

We ask for the level of using big data analytics in internal audit. Because of needing more improvements, settling the system entirely and as the process of building awareness continues, they note 3 out of 5 . The average of the contribution of the use of data analytics to internal audit department is 7,3 out of 10 . Participant 8 who works as an SAP consultant give 3 out of 10 . So we understand that the perception of participants is different according to their job position and which department they work.

We ask for the strategic goals that BDA served regarding the internal audit. Minimizing the human error, fraud detection, lowering costs, getting accurate results, participating in the audit activities more effectively and time-saving are the main answers that we collect for the strategic goals that BDA served.

In terms of the tasks for big data analytics, according to participant 1, the primary advantage of BDA is the testing of the entire population. Although not for all of the company the vast majority is used BDA, so most of our cases sampling is not necessary thanks to BDA technologies. According to participant 2, real-time intervention is performed directly through the system thanks to BDA technologies.

For the place of BDA in internal audit budget, according to participant 1, 2 and 6, the central place in the budget of internal audit is the personnel costs. BDA possess a smaller amount compared to the total budget. The share of BDA in internal control and financial reporting is nearly $10 \%$ of the total budget of their company. The other participants have no answer to this question.

When we ask the issues about reaching data within the company, according to participant 2 company has the data that can be accessed by the manager and top-level managers. So some data and information have known the only top level, this can be the cause of some problems. Integration problems with new systems cause some issues about reaching data. According to participant 4, IT related coordination problems are the main issues about reaching data. Participant 5 and 6 underline that standards of data entry should be developed for BDA works correctly and training for this purposes is important.

When we ask certificates and licenses which are essential for internal audit, we find that our participants have mainly the CIA and CPA licenses and they declared that excel, SAP training, knowledge of computer language are important for internal audit.

\section{CONCLUSION}

The study shows that internal auditors are mostly aware of the importance of big data analytics, the different policies and methods of its implementation into the organization and its role in transforming internal audit function. Accordingly, it is expected that BDA facilitates the internal audit function and contribute to the effectiveness of risk management, controls, governance process and fraud detection.

\section{Acknowledgment}

This work has been realized with the support of Galatasaray University Scientific Research Fund. [grant number 18.102.003].

\section{REFERENCES}

Alves, M. D. C. G., Matos, S. I. A. (2010). Adoption of enterprise resource planning system - some preliminary results. Proceedings of the European Conference on Information Management \& Evaluation.

Cangemi, M. P. (2016). Views on internal audit, internal controls, and internal audit's use of technology EDPACS. vol. 53 , no. 1.

Protiviti (2017). 2017 Internal Audit Capabilities and Needs Survey. Available https://www.protiviti.com/sites/default/files/united_states/insights/2017-internal-audit-capabilities-and-needs-survey-protiviti.pdf

Sun, Z., Sun, L., Strang, K., (2018). Big data analytics services for enhancing business intelligence. Journal of Computer Information Systems Vol. 58, no. 2 .

Tang, F., Norman, C. S., Vendrzyk, V. P. (2017). Exploring perceptions of data analytics in the internal audit function. Behaviour \& Information Technology, vol. 36, no. 11, p. 1125-1136. 